\title{
An efficient and accurate solver for large, sparse neural networks
}

\author{
Roman M Stolyarov ${ }^{1,2}$, Andrea K Barreiro ${ }^{1 *}$, Scott Norris ${ }^{1}$ \\ From 24th Annual Computational Neuroscience Meeting: CNS*2015 \\ Prague, Czech Republic. 18-23 July 2015
}

The mammalian brain has about $10^{11}$ neurons and $10^{14}$ synapses, with each neuron presenting complex intracellular dynamics. The huge number of structures and interactions underlying nervous system function thus make modeling its behavior an extraordinary computational challenge. One strategy to reduce computation time in networks is to replace computationally expensive, stiff models for individual cells (such as the Hodgkin-Huxley equations and other conductance-based models) with integrate-and-fire models. Such models save time by not numerically resolving neural behavior during its action potential; instead, they simply detect the occurrence of an action potential, and propagate its effects to postsynaptic targets appropriately. Thus, a complicated system of continuous ordinary differential equations is replaced with a simpler, but discontinuous, differential equation.

However, accurate existing methods for integrating discontinuous ordinary differential equations (ODEs) scale poorly with problem size, requiring $\mathrm{O}\left(\mathrm{N}^{2}\right)$ time steps for a system with $\mathrm{N}$ variables. The underlying challenge is that discontinuities introduce $\mathrm{O}(\mathrm{dt})$ errors to conventional time integration schemes, thus requiring very small time steps in the vicinity of a discontinuity [1].

In this work, we propose a method to reduce this computational load by embedding local network "repairs" within a global time-stepping scheme. In addition, highorder accuracy can be achieved without requiring the
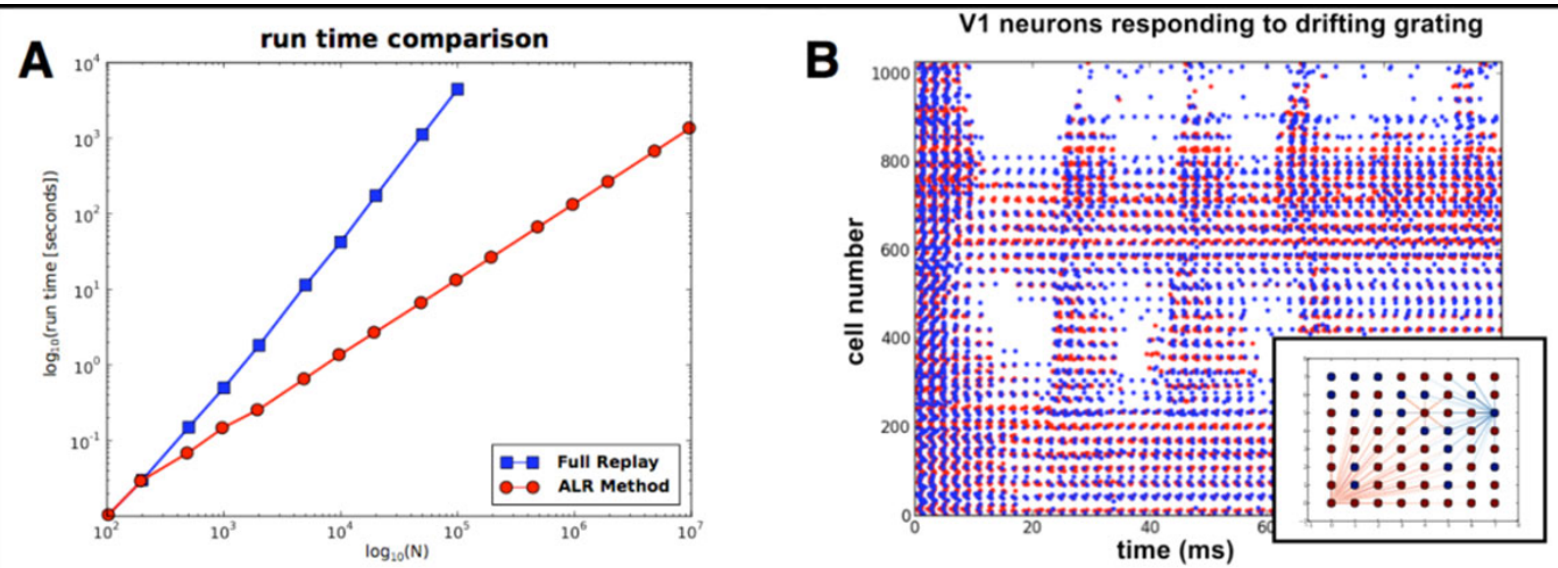

Figure 1 (A) Comparison of runtime for a fully event-driven ("Full Replay") and ALR methods, for integrate-and-fire networks of various system sizes $\mathbf{N}$. (B) Raster plot of a $32 \times 32$ grid of $\mathrm{V} 1$ model neurons responding to a drifting grating stimulus. Inset: schematic of a subset of the network, with selected synapses identified and shaded by strength. Red: AMPA; orange: NMDA, blue: fast GABA.

\footnotetext{
* Correspondence: abarreiro@smu.edu

'Department of Mathematics, Southern Methodist University, Dallas, TX, USA

Full list of author information is available at the end of the article
} 
global time step to be bounded above by the minimum communication delay, as is currently required in the hybrid time-driven/event-driven scheme used by NEST [2]: this allows more powerful exploitation of exact subthreshold [3,4] and quadrature-based [5] integration schemes. If the underlying network is sufficiently sparse the algorithm, Adaptive Localized Replay (ALR), will attain time complexity $\mathrm{O}(\mathrm{N})$ (Figure $1 \mathrm{~A})$. We apply our method to a network of integrate-and-fire neurons that simulates dynamics of a small patch of primary visual cortex (Figure 1B) $[5,6]$.

\section{Acknowledgements}

This work was supported by the SMU Hamilton Undergraduate Research

Scholars Program (RS).

\section{Authors' details}

'Department of Mathematics, Southern Methodist University, Dallas, TX, USA.

${ }^{2}$ Harvard-MIT Department of Health Sciences and Technology, Cambridge,

MA, USA.

Published: 18 December 2015

\section{References}

1. Shelley MJ, Tao L: Efficient and accurate time-stepping schemes for integrate-and-fire neuronal networks. J Comp Neurosci 2001, 11(2):111-119.

2. Gewaltig MO, Diesmann M: NEST (NEural Simulation Tool). Scholarpedia 2007, 2(4):1430.

3. Brette R: Exact simulation of integrate-and-fire models with synaptic conductances. Neural Computation 2006, 18(8):2004-2027.

4. Morrison A, Straube S, Plesser HE, Diesmann M: Exact subthreshold integration with continuous spike times in discrete-time neural network simulations. Neural Computation 2007, 19(1):47-79.

5. Rangan $A V$, Cai $D$ : Fast numerical methods for simulating large-scale integrate-and-fire neuronal networks. J Comp Neurosci 2007, 22(1):81-100.

6. Cai D, Rangan AV, McLaughlin DW: Architectural and synaptic mechanisms underlying coherent spiking activity in V1. Proceedings of the National Academy of Sciences 2005, 102(16):5868-5873.

doi:10.1186/1471-2202-16-S1-P179

Cite this article as: Stolyarov et al:: An efficient and accurate solver for large, sparse neural networks. BMC Neuroscience 2015 16(Suppl 1):P179.

\section{Submit your next manuscript to BioMed Central} and take full advantage of:

- Convenient online submission

- Thorough peer review

- No space constraints or color figure charges

- Immediate publication on acceptance

- Inclusion in PubMed, CAS, Scopus and Google Scholar

- Research which is freely available for redistribution

Submit your manuscript at www.biomedcentral.com/submit 